
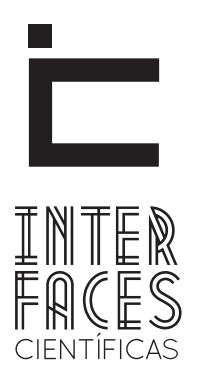

EXATAS E TECNOLÓGICAS

ISSN IMPRESSO - 2359-4934

ISSN ELETRÔNICO - 2359-4942

DOI-10.17564/2359-4942.2018v3n1p27-34

\title{
MAQUUAGEM VERDE EM ANÚNCIOS PUBLLCTTÁRIOS: INFLUÊNCIA NA SOCIEDADE SOB ENFOQUE DA ANÁLISE CRÍTICA DO DISCURSO
}

\author{
GREENWASHING IN ADVERTISEMENTS: INFLUENCE IN SOCIETY UNDER THE FOCUS OF CRITICAL DISCOURSE ANALYSIS \\ MAQUILLAJE VERDE EN ANUNCIOS PUBLICITARIOS: INFLUENCIA EN LA SOCIEDAD BAJO EL ENFOQUE DEL ANÁLISIS CRíTICO DEL DISCURSO
}

\section{RESUMO}

O objetivo central deste trabalho é observar, dentro do contexto da Análise Crítica do Discurso de Norman Fairclough, a prevalência da chamada maquiagem verde no mercado publicitário brasileiro (tanto de anúncios como dos rótulos), identificando, sob as três dimensões - textual, discursiva e social -, os sentidos discursivos e ideológicos da propaganda que é o corpus da pesquisa: a peça publicitária da borracha "Architecte", da empresa "Maped". O estudo se deu no campo analítico do método qualitativo, e os resultados obtidos apontam à obsessão das empresas produtoras por atingir os consumidores brasileiros no campo ambiental, já que estes estão entre os que mais procuram saber a origem ecológica dos produtos que consomem. No caso da Maped, observou-se que a manipulação com uso de falso selo, de mecanismos de cores e dizeres aludindo a um padrão confiável de empresa amiga do meio ambiente tem sido um caminho fácil de engano aos consumidores, os quais, desavisadamente, acabam sendo influenciados pelo falso discurso ecológico do mercado.

\section{PALAVRAS-CHAVE}

publicidade verde, maquiagem ambiental, ecológico 


\section{ABSTRACT}

The main objective of this work is to observe, within the context of Norman Fairclough's Critical Discourse Analysis, the prevalence of so-called greenwashing in the Brazilian advertising market (both ads and labels), identifying, under the three dimensions - textual, discursive and social - the discursive and ideological senses of the advertising that is the corpus of the research: the erase advertising piece "Architecte", of the company "Maped". The study was carried out in the analytical field of the qualitative method, and the results obtained point to the obsession of the producing companies to reach the Brazilian consumers in the environmental field, since these are among the ones that more seek to know the ecological origin of the products they consume. In the case of "Maped", it has been observed that the manipulation with the use of false seal, with mechanisms of colors and sayings alluding to a trustworthy standard of company friendly to the environment has been an easy way of deceiving to the consumers, who, unwittingly, end up being influenced by the false ecological discourse of the market.

\section{KEYWORDS}

Green Advertising. Environmental makeup. Ecological

\section{RESUMEN}

El objetivo central de este trabajo es observar, dentro del contexto del Análisis Crítico del Discurso de Norman Fairclough, la prevalencia del Ilamado maquillaje verde en el mercado publicitario brasileño (tanto de anuncios y de los rótulos), identificando, bajo las tres dimensiones-textual, discursiva y discursiva, social, los sentidos discursivos e ideológicos de la propaganda que es el corpus de la investigación: la pieza publicitaria del caucho "Architecte", de la empresa "Maped". El estudio se dio en el campo analítico del método cualitativo, y los resultados obtenidos apunta a la obsesión de las empresas productoras por alcanzar a los consumidores brasileños en el campo ambiental, ya que éstos están entre los que más buscan saber el origen ecológico de los productos que consumen. En el caso de "Maped”, se observó que la manipulación con uso de falso sello, de mecanismos de colores y palabras aludiendo a un estándar confiable de empresa amiga del medio ambiente ha sido un camino fácil de engaño a los consumidores, que, desvinculadamente, acaban siendo influenciados por el falso discurso ecológico del mercado.

\section{DESCRIPTORES}

publicidad verde, maquillaje ambiental, ecológico 


\section{INTRODUÇ̄̃O}

Desde os primórdios, a publicidade é utilizada como meio de convencimento da população a agir da forma que está expressa por trás das palavras - a forma idealizada por seus criadores. A procura maciça foi criada quase totalmente pelo desenvolvimento da publicidade (COOLIDGE, 1929). De venda de algum produto a anúncios de shows de uma banda da moda, a publicidade está enraizada na sociedade global.

Historicamente, a publicidade e seus efeitos passaram a ganhar destaque durante a Revolução Francesa de 1789, quando cartazes contra a rainha Maria Antonieta circulavam por toda Paris. De lá para cá, muito se desenvolveu, e os adventos da televisão, do rádio e, mais recentemente, da internet criaram novos canais de distribuição das propagandas, atingindo um público cada vez maior, já que a publicidade é uma das formas mais interessantes e difíceis da literatura moderna (HUXLEY, 2017).

Dentro do conceito de publicidade, há a propaganda ambiental. Ela tem como base a promoção de produtos com base em seus atributos ambientais, sendo considerados "amigos do meio ambiente". A publicidade ambiental, portanto, passa uma nova impressão da imagem da empresa, fazendo com que os consumidores passem cada vez mais a confiar nela e em seus produtos, tendo normalmente um setor específico dentro da empresa que cuida do Ecomarketing (outra designação para o termo), levando em conta o fato de que criatividade publicitária é saber ver além do óbvio (PERISCINOTO, 1995).

$O$ marketing ambiental, quando feito de forma bem fundada, pode levar uma pequena empresa a se tornar líder do seu setor no futuro, desde que seja plenamente uma empresa ambientalmente responsável, posto que para o bem ou para o mal, suas palavras são a sua propaganda. Todas as vezes que abre a boca, você revela 0 que existe em sua mente (BARTON, 2017).

Entretanto, isso não quer dizer que todas as empresas irão seguir à risca a sua política de marketing ambiental. É então onde nasce a chamada maquiagem verde, um conceito trazido nos últimos anos pela globalização a nível mundial, onde "uma promessa, uma grande promessa, é a alma de um anúncio” (JO-
HNSON, 1796, p. 225). Com um crescimento de $478 \%$ entre 2010 e 2014, essa prática tem dado bons frutos às empresas praticantes no Brasil, que se utilizam de técnicas para mascarar, enganar acerca da origem verde de seus produtos, visando ao convencimento do comprador de que a empresa é verde e "amiga do meio ambiente”. Devido à crescente intensificação dessa prática no mercado publicitário, a maquiagem verde já ganhou até uma classificação: os chamados "Sete Pecados da Maquiagem Verde". São eles:

1. Custo ambiental camuflado;

2. Falta de prova;

3. Incerteza;

4. Culto a falsos rótulos;

5. Irrelevância;

6. "Menos pior";

7. Mentira.

\section{MÉTODO}

Com base nesses conceitos, este trabalho ganha corpo, unindo-os à Análise Crítica do Discurso (ACD), de Norman Fairclough, objetivando identificar ideologias, contextos, alusões e analogias com base nas palavras, na construção de qualquer meio de comunicação, incluindo também os anúncios publicitários. A ACD se estrutura sob três dimensões principais de análise: textual (que investiga o vocabulário e a conjunto do texto), discursiva (que procura por analogias e elementos interdiscursivos no texto) e social (que analisa o texto com base em conceitos sociais que venham a ser encontrados dentro dele). "O discurso constitui o social [] e é formado por relações de poder e investido de ideologias" (FAIRCLOGH, 1992, p. 8).

\section{RESULTADOS}

Nesse contexto, a pesquisa do trabalho tentou identificar, utilizando a importante ferramenta da internet, empresas que atuassem com a maquiagem verde em seus anúncios. Assim, foi encontrada matéria do site EcoDebate em que estavam listadas 
propagandas denunciadas ao Conselho Nacional de Autorregulamentação Publicitária (CONAR) e que se encaixavam nas características procuradas. A peça escolhida para o desenvolvimento deste trabalho de análise foi a da borracha escolar "Architecte", da empresa “Maped” (FIGURA 1).

Por considerarmos, assim como afirma a ACD, que o discurso fundamentado em caráter ideológico, contextualizado socialmente e marcado por relações de poder, observaremos a peça publicitária sob tal prisma, considerando a produção e o consumo do discurso produzido publicitariamente, no contexto do ecologicamente correto. As ideologias que norteiam a produção e a interpretação dos discursos, seu caráter implícito que leva muitos a reproduzirem ideologias estão inegavelmente vinculadas ao princípio hegemônico e de poder. Dessa forma, pode-se observar como é feito o apelo pela estratégia de "marketing" e identificar qual o impacto na escolha do consumidor embasado no argumento ecológico. As categorias expressas nas dimensões, como podemos observar no Quadro 1, é o marco do estudo.

Quadro 1 - Categorias analíticas propostas no modelo tridimensional

\begin{tabular}{|c|c|c|}
\hline TEXTO & $\begin{array}{c}\text { PRATICA } \\
\text { DISCURSIVA }\end{array}$ & PRATICA SOCIAL \\
\hline $\begin{array}{c}\text { Vocabulário } \\
\text { Gramática } \\
\text { Coesáo } \\
\text { Estrutura } \\
\text { textual }\end{array}$ & $\begin{array}{l}\text { Produção } \\
\text { Distribuição } \\
\text { Consumo } \\
\text { Contexto } \\
\text { Força } \\
\text { Coerência } \\
\text { Intertextualidade }\end{array}$ & $\begin{array}{l}\text { Ideologia } \\
\text { Sentidos } \\
\text { Pressuposiçøes } \\
\quad \text { Metáfora } \\
\text { Hegemonia } \\
\text { Orientaçøes econômicas, políticas, } \\
\text { culturais, ideológicas. }\end{array}$ \\
\hline
\end{tabular}

Fonte: Fairclough (2001).

$\mathrm{Na}$ construção da propaganda em torno da borracha, foi utilizada a informação de que ela é totalmente livre de PVC, sendo que isso está estampado em um formato de selo na imagem. Tal fato, porém, é destacado como um falso diferencial em relação às concorrentes, já que marcas como a "Faber Castell" também não utilizam o PVC em suas composições, mas sem utilizar de tal recurso para chamar a atenção dos consumidores.
Figura 1 - Publicidade da borracha Architecte

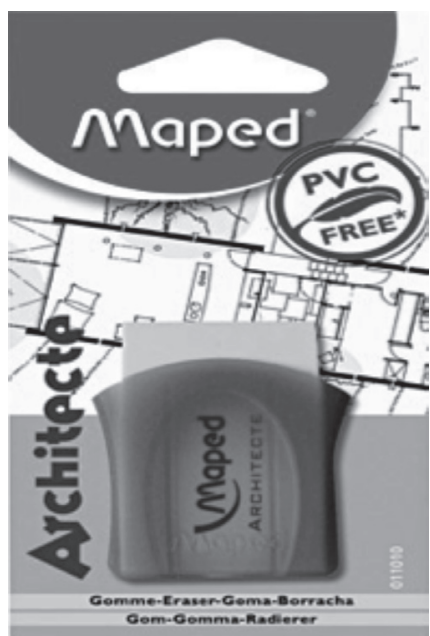

Fonte:https://www.kalunga.com.br/prod/borracha-architecte-011010-maped/072304

\section{DISCUSSÃO}

Para facilitar a compreensão das ideias desenvolvidas, o tópico “Discussão" foi dividido em subtópicos de acordo com a área abordada, como segue.

\subsection{DIMENSÃO TEXTUAL}

A publicidade da borracha possui um vocabulário bastante restritivo, com pouquíssimas palavras, sem uma estrutura conectiva aparente, sendo este fato justificado por o produto ser voltado para um nicho, além do fácil acesso que a borracha deve ter. $\mathrm{Na}$ exibição do selo "PVC FREE”, a língua inglesa é utilizada como código para expressão da mensagem, enquanto que no rodapé há a tradução da palavra borracha para inúmeras línguas. A elaboração de um selo onde se coloca o desenho de uma pena, tudo na cor verde, é um mecanismo textual importante na elaboração da ideia que se deseja passar de compromisso ambiental da empresa. 


\subsection{DIMENSÃO DISCURSIVA}

O verde do selo na parte superior, estrategicamente colocado próximo à tarja vermelha com o logotipo da empresa alude ao conceito ambiental, tentando levar o consumidor a pensar que a postura sustentável da empresa é verdadeira e legitimada com um selo. A composição básica do desenho do selo - com uma folha indicando o cunho ambiental - sugere a relação desse símbolo com a oficialização ecológica, de forma a levar o consumidor a acreditar que o produto teria passado por uma análise de órgãos de controle governamentais, com ausência de selos como o Cerflor e o FSC (FIGURAS 2; 3). Tudo isso se configura maquiagem verde no anúncio do produto.

Figura 2 - Selo oficial do Cerflor, de responsabilidade do Inmetro

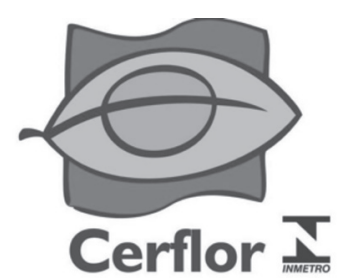

Fonte: https://oglobo.globo.com/sociedade/ciencia/revista-amanha/certificados-ambientais-11-selos-que-voce-precisa-conhecer-9623714

Figura 3 - Selo do FSC

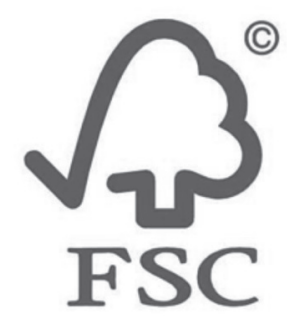

Fonte:https://www.innocentdrinks.co.uk/ blog/2012/april/our-carton-family
A única informação encontrada quanto à distribuição foi a presença da borracha no site de compras “Kalunga.com”, mas é possível deduzir que o produto está presente nas lojas de materiais escolares, não sendo identificada nos termos desta pesquisa nenhuma veiculação da publicidade em termos televisivos e no rádio, pelo menos em nível nacional. Isso é justificado por se tratar de um produto específico para estudantes, sendo um material escolar. Entretanto, o fato de ser um material de cunho educacional coloca os alunos à exposição da maquiagem verde.

\subsection{DIMENSÃO SOCIAL}

Socialmente falando, a utilização do selo indicando ser livre de PVC demonstra a obsessão das empresas produtoras por atingir os consumidores brasileiros no campo ambiental, já que estes estão entre os que mais procuram saber a origem ecológica dos produtos que consomem. Além disso, a maquiagem verde em geral demonstra o famoso "jeitinho brasileiro" para passar por cima dos problemas, visando atingir os objetivos pré-estabelecidos - nesse caso, a venda do produto. Dentro da ideia dos "Sete Pecados da Maquiagem Verde", a publicidade se encaixa na chamada Irrelevância, já que passa uma informação que, verdadeira, não acrescenta em nada na escolha final do consumidor, além de não ser algo único dentro do mercado.

\section{CONCLUSÃO}

Conclui-se, portanto, que é de suma importância a informação do público quanto à maquiagem verde nos produtos que consome, principalmente, levando em conta a situação atual do meio ambiente no planeta, dessa forma, estando atentos para a origem deles. Além disso, percebeu-se na produção da pesquisa o fato de a maquiagem verde poder atingir até crianças, estando elas, vulneráveis a seu impacto em meio aos materiais escolares comprados.

A publicidade, portanto, deve sempre procurar por novas e criativas técnicas para chamar a 
atenção de seu público, porém sem utilizar mão de estratégias como a maquiagem verde, principalmente, considerando a já mencionada degradação ambiental. Com poucas palavras impressas no anúncio, juntamente às leis que são aprovadas diariamente acerca do tema, unidas à apresentação diária da importância de um consumo consciente, o público acaba induzido à compra. Dessa forma, a manipulação causada por tais produtos corrobora a corrupção inerente da sociedade brasileira.

\section{REFERÊNCIAS}

ALCÂNTARA, Maria Isabel; BALBINO, Michele. A publicidade verde e os direitos do consumidor. Disponível em: <http://www.ambito-juridico. com.br/site/index.php?n_link=revista_artigos_ leitura\&artigo_id=9133>. Acesso em: 28 nov. 2017.

AMBIENTE BRASIL. Marketing ambiental. Disponível em: <http://ambientes.ambientebrasil.com.br/ gestao/artigos/marketing_ambiental.html>. Acesso em: 28 nov. 2017.

BARTON, Bruce. Pensador. Disponível em: <https:// www.pensador.com/frase/NzY3NDAy/ >.

Acesso em: 28 nov. 2017.

Coolidge C. The Autobiography of Calvin Coolidge. Cosmopolitan book corp.; 1929.

\section{ECODEBATE. Proteste denuncia ao Conar produtos com apelos ecológicos enganosos na embalagem. Disponível em: <https://www.ecodebate.com. br/2016/03/18/proteste-denuncia-ao-conar- produtos-com-apelos-ecologicos-enganosos-na- embalagem/>. Acesso em: 28 nov. 2017.}

\section{EQUIPE ECYCLE. Saiba o que é}

greenwashing. Disponivel em: <https://

www.ecycle.com.br/component/content/ article/35-atitude/2094-definicao-o-que como-traducao-greenwashing-estrategias- marketing-propaganda-consumo-produtos-servicosatitude-apelo-ambiental-enganosa-empresasconsciencia-ambiental-casos-exemplos-cuidados. html>. Acesso em: 28 nov. 2017.

FAIRCLOUGH, Norman. Discourse and social change. Vol. 10. Cambridge: Polity press, 1992.

\section{FAIRCLOUGH, Norman. Discurso e mudança social.}

Brasília: Universidade de Brasília, 2001.

HUXLEY, Aldous. Citador. Disponível em: <http:// www.citador.pt/frases/a-publicidade-e-uma-dasformas-mais-interessantes-aldous-huxley-7441>. Acesso em: 28 nov. 2017.

JOHNSON, Samuel. The idler. Vol. 7. T. Longman [and 51 others], 1796.

\section{PEDROSA, Cleide. Uma proposta para a análise crítica} da linguagem. Disponível em: <http://www.filologia. org.br/ixcnlf/3/04.htm>. Acesso em: 28 nov. 2017.

PERISCINOTO, Alex. Mais vale o que se aprende que o que te ensinam. São Paulo: Editora Best Seller, 1995. PUMES, Luka; ALBELLA, Lorenzo; MARTINS, Rafael. Os apelos da maquiagem verde. Disponível em: <https://jornalismoambiental.uniritter.edu. br/?p=1971>. Acesso em: 28 nov. 2017.

\section{REVISTA DO MEIO AMBIENTE. Os sete pecados} da maquiagem verde empresarial. Disponível em: <http://revista.rebia.org.br/capa/126-os-setepecados-da-maquiagem-verde-empresarial>. Acesso em: 28 nov. 2017.

WIKIPÉDIA. Publicidade. Disponível em: <https:// pt.wikipedia.org/wiki/Publicidade>.

Acesso em: 28 nov. 2017. 
Recebido em: 6 de Fevreiro 2018

Avaliado em: 12 de Maio 2018

Aceito em: 26 de Maio 2018
1 Estudante; Instituto Federal do Sertão Pernambucano - Campus Floresta. E-mail: albaleal2707@gmail.com

2 Estudante; Instituto Federal do Sertão Pernambucano - Campus Floresta. E-mail: ph.vianei@hotmail.com 
